\title{
Sequential $\mathrm{Cu}(\mathrm{I}) / \mathrm{Pd}(0)$-Catalyzed Multicomponent Coupling and Annulation Protocol for the Synthesis of Indenoisoquinolines
}

\author{
Thiruvellore Thatai Jayanth, Lei Zhang, Thomas S. Johnson ${ }^{\ddagger}$, and Helena C. Malinakova \\ Department of Chemistry, University of Kansas, 1251 Wescoe Hall Drive, Lawrence, Kansas, \\ 66045 and the Center for Methodology and Library Development at the University of Kansas, \\ 2121 Simons Drive, Lawrence, Kansas 66047
}

\begin{abstract}

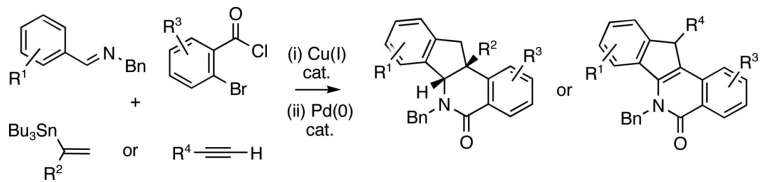

Copper-catalyzed coupling of imines, vinylstannanes or alkynes and $o$-bromoaroyl chlorides followed by $\operatorname{Pd}(0)$-catalyzed annulations afforded indenoisoquinolines. Protocols requiring minimal purifications were developed, providing new methods for the construction of combinatorial libraries.
\end{abstract}

The prevalance of $N$-heterocycles among established pharmaceutical agents ${ }^{1}$ continues to inspire the development of new synthetic methods. We have been exploring a protocol based on an assembly of a- $N$-substituted amides followed by various intramolecular cyclizations, ${ }^{2}$ opening up access to combinatorial libraries of hexahydro- $1 \mathrm{H}$-isoindolones (Figure 1). ${ }^{3}$

Herein, we describe a powerful novel combination of the $\mathrm{Cu}(\mathrm{I})$-catalyzed three-component coupling and an intramolecular $\operatorname{Pd}(0)$-catalyzed 1,2-bisarylation of an olefin or an alkyne in amides IV and $\mathbf{V}$ to deliver substituted indenoisoquinolines VI and VII (Figures 1 and 2). The protocol allows a rapid increase in molecular complexity in only two steps.

Structurally related indenoisoquinolines have been shown to possess potent biological activities. ${ }^{4}$ Our protocol provides a more efficient alternative to the established preparations of indenoisoquinolines, particularly those substituted at the angular position or the benzylic carbon in the indene ring. ${ }^{5}$ The method reported herein opens up a modular access to indenoisoquinolines, and is well amenable to automation.

Initial studies were focused on extending the scope of the known $\mathrm{Cu}(\mathrm{I})$-catalyzed coupling 6 to $o$-bromoaroyl chlorides III as well as to 1,1-disubstituted vinylstannanes II (Figure 2). We were able to decrease the molar excess of stannane $3 \mathbf{a},{ }^{7}$ from 2.0 equiv to 1.5 equiv $^{8}$ and realize the coupling to imine 1a and aroyl chloride 2a providing amide $\mathbf{4 a}$ in good yields (Scheme 1). An increase in the $\mathrm{CuCl}$ catalyst load improved the yield of amide $\mathbf{4 a}$ from $67 \%$ (with $10 \mathrm{~mol} \% \mathrm{CuCl}$ ) and to $82 \%$ (with $20 \mathrm{~mol} \% \mathrm{CuCl}$, Scheme 1). ${ }^{9} \mathrm{Next}$, the Pd-

Correspondence to: Helena C. Malinakova.

hmalina@ku.edu.

‡Undergraduate research participant (NSF-REU), Grinnell College.

Supporting Information Available Description of the synthesis and characterization of all new compounds. and X-ray crystallographic analyses on compounds $\mathbf{5 j}, \mathbf{5 n}$ and $\mathbf{8 c}$. This material is available free of charge via the Internet at http://pubs.acs.org. 
catalyzed cyclization of amide $\mathbf{4}$ a was explored, anticipating that an intramolecular Heck reaction would afford intermediate VIII poised for electrophilic arylation to yield dihydroindeno[1,2-c]isoquinolines VI (Figure 2). ${ }^{10}$ The treatment of amide 4a with $\mathrm{Pd}(\mathrm{OAc})_{2}(5 \%)$ and $\mathrm{NaOAc}(1$ equiv) afforded the indenoisoquinoline $5 \mathbf{a}$ in a $93 \%$ yield as a single diastereomer (Scheme 1). ${ }^{11}$

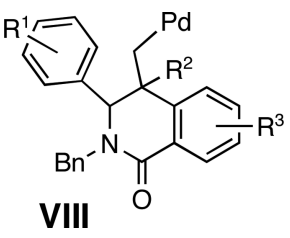

Aiming to establish a protocol amenable to automated synthesis, we sought to eliminate chromatographic purification of amide 4a. The addition of solid KF and small quantities of water, followed by filtration was employed to remove tin residues from the reaction mixtures. The resulting crude amide $\mathbf{4 a}$ was treated with $\mathrm{Pd}(\mathrm{OAc})_{2}$ catalyst under conditions reported in Scheme 1 to afford indenoisoquinoline 5a in 75\% yield over two steps (entry 1, Table 1, Method A). A brief survey revealed that sodium acetate was the optimum base for the Pd-catalyzed cyclization. ${ }^{10}$ The replacement of $\mathrm{NaOAc}$ with $\mathrm{Na}_{2} \mathrm{CO}_{3} / n-\mathrm{Bu}_{4} \mathrm{NCl}$ applying modified Jeffery's conditions ${ }^{12}$ (compare Methods A and B, entries 1, 3 and 4, Table 1) resulted in a decrease in the reaction yields, particularly severe for the electronically deactivated imines $\mathbf{1 c}\left(\mathrm{R}^{2}=\mathrm{H}\right)$ and $\mathbf{1 d}\left(\mathrm{R}^{2}=\mathrm{Cl}\right)$ (entries 3 and 4, Method $\mathrm{B}$, Table 1). Overall, the optimized sequential protocol afforded the corresponding indenoisoquinolines 5a-5e in 38-75\% yields over two steps (entries 1-5, Table 1, Method A). The lower yields of the electronically deactivated chloro and ester-substituted indenoisoquinolines 5d-e are in agreement with the proposed involvement of electrophilic palladation in the key step, although the less facile iminolysis of the acyl chlorides may also be a contributing factor. The 3,4-disubstituted imines $\mathbf{1 f}$ and $\mathbf{1 g}$ afforded single regioisomers of heterocycles $\mathbf{5 f}(\mathbf{7 7 \%})$ and $\mathbf{5 g}(71 \%)$ arising from palladation at the least hindered position in the aromatic ring (entries 6 and 7, Table 1). A contiguous 1,2,3,4,5-substitution pattern was achieved in an activated imine yielding indenoisoquinoline $\mathbf{5 h}$ in $64 \%$ yield (entry 8, Table 1). Efficient preparation of indenoisoquinolines $\mathbf{5} \mathbf{i}$ and $\mathbf{5} \mathbf{j}$ demonstrated the compatibility of the method with heteroatoms other than oxygen (entries 9 and 10, Table 1).

To expand the reaction scope, imines $\mathbf{1 a}$ and $\mathbf{1 b}$ were coupled to substituted aroyl chlorides $\mathbf{2 b}-\mathbf{c}$ and vinylstannanes $\mathbf{3 a}$ and $\mathbf{3 b}-\mathbf{c}^{13}$ bearing aliphatic $(\mathrm{Me})$ and aromatic $(\mathrm{Ph})$ substituents. Indenoisoquinolines 5k-o were obtained in good yields (59-76\%) over two steps (Table 2). Heterocycles $\mathbf{5 k - 0}$ were isolated as single diastereomers following chromatography and trituration of the crude products. The relative stereochemistry in heterocycles $5\left(\mathrm{R}^{4}=\mathrm{COOEt}\right.$ and $\mathrm{Ph}$, Tables 1 and 2$)$ was assigned based on analogy with indenoisoquinolines $\mathbf{5 j}$ and $\mathbf{5 n}$, the structure of which was elucidated via single crystal $X$-ray crystallographic analyses. The relative stereochemistry in products $5 \mathbf{~ m}$ and $5 \mathrm{o}\left(\mathrm{R}^{4}=\mathrm{Me}\right)$ was assigned via spectroscopic methods. ${ }^{14}$

To access a distinct substitution pattern in the indenoisoquinolines, propargyl amide $\mathbf{7}$ a was prepared from imine 1a, aroyl chloride $\mathbf{2 a}$ and alkyne $\mathbf{6 a}$ in a good yield (54\%) using conditions reported by Arndtsen ${ }^{15}$ (Scheme 2). We envisioned that Pd-catalyzed intramolecular bisfunctionalization of the alkyne ${ }^{16}$ would proceed via intermediate $\mathbf{I X}$ to afford indenoisoquinolines VII (Figure 2). Conceivably, a 1,3-shift of the allylic hydrogen in the intermediate $\mathbf{I} \mathbf{X}$ would provide an organopalladium intermediate poised for the terminal electrophilic palladation. 


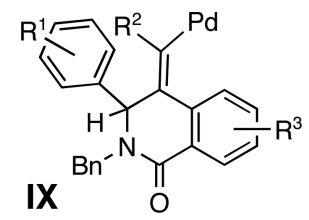

Indeed, the treatment of amide $7 \mathbf{a}$ with $\mathrm{Pd}(\mathrm{OAc})_{2}$ catalyst and $\mathrm{Na}_{2} \mathrm{CO}_{3} / n-\mathrm{Bu}_{4} \mathrm{NCl}$ additive mixture for a prolonged time period $\left(36 \mathrm{~h}\right.$ at $120^{\circ} \mathrm{C}$ in $\left.\mathrm{DMF}\right)$ afforded the corresponding indenoisoquinoline 8a in an excellent yield (91\%) (Scheme 2). Ultimately, the isolation of amide 7a was avoided, limiting the purification of the crude reaction mixtures to the removal of excess alkyne via filtration through a short plug of silica. The resulting crude product was directly subjected to Pd-catalysis, affording indenoisoquinoline 8a in a good yield $(66 \%)$ over two steps (entry 1, Table 2 ). This protocol was then applied to the coupling of imines $\mathbf{1 a}, \mathbf{1 b}$ and $\mathbf{1} \mathbf{j}$ with aroyl chloride $\mathbf{2 a}$ and aryl acetylenes $\mathbf{6 a - 6 \mathbf { c }}$ to provide indenoisoquinolines 8a-e in good yields (51-68\%) over two steps (Table 2). Single crystal $\mathrm{X}$-ray crystallographic studies on heterocycle $\mathbf{8 c}$ unequivocally established the structure, including the position of the double bond within the isoquinoline ring. ${ }^{17}$

The new synthetic protocol described here rapidly and efficiently assembles indenoisoquinolines with distinct substitution patterns from three simple building blocks. The modular strategy is particularly well suited for the construction of combinatorial libraries of indenoisoquinolines.

\section{Supplementary Material}

Refer to Web version on PubMed Central for supplementary material.

\section{Acknowledgments}

Support for this work from the National Institutes of Health (KU Center for Methodology and Library Development, Grant No. P 50 GM069663) is gratefully acknowledged. We thank our colleague Dr. Victor W. Day for his assistance with the X-ray crystallographic analyses.

\section{References}

1. Taylor, JB.; Triggle, DJ., editors. Comprehensive Medicinal Chemistry II. Elsevier; Amsterdam, Boston: 2007.

2. Martin SF, Sunderhause JD, Dockendorff C. Org. Lett. 2007; 9:4223. [PubMed: 17887692]

3. a Zhang L, Lushington GH, Neuenswander B, Hershberger JC, Malinakova HC. J. Comb. Chem. 2008; 10:285. [PubMed: 18237142] b Zhang L, Malinakova HC. J. Org. Chem. 2007; 72:1484. [PubMed: 17243720]

4. a Ryckebusch A, Garcin D, Lansiaux A, Goossens J-F, Baldeyrou B, Houssin R, Bailly C, Henichart J-P. J. Med. Chem. 2008; 51:3617. [PubMed: 18507368] b Teicher BA. Biochem. Pharmacol. 2008; 75:1262. [PubMed: 18061144] c Antony S, Agama KK, Miao Z-H, Takagi K, Wright MH, Robles AI, Varticovski L, Nagarajan M, Morrell A, Cushman M, Pommier Y. Cancer. Res. 2007; 67:10397. [PubMed: 17974983]

5. a D'Souza DM, Kiel A, Herten D-P, Rominger F, Müller TJJ. Chem. Eur. J. 2008; 14:529. [PubMed: 17933002] b Morrell A, Placzek M, Parmley S, Grella B, Antony S, Pommier Y, Cushman M. J. Med. Chem. 2007; 50:4388. [PubMed: 17676830] c D'Souza DM, Rominger F, Müller TJJ. Angew. Chem. Int. Ed. 2005; 44:153.d Xiao X, Miao Z-H, Antony S, Pommier Y, Cushman M. Bioorg. Med. Chem. Lett. 2005; 15:2795. [PubMed: 15911256] e Jagtap PG, Baloglu E, Southan G, Williams W, Roy A, Nivorozhkin A, Landrau N, Desisto K, Saltzman AL, Szabo C. Org. Lett. 2005; 7:1753. [PubMed: 15844898] f Xiao X, Antony S, Kohlhagen G, Pommier Y, Cushman M. Bioorg. Med. Chem. 2004; 12:5147. [PubMed: 15351398] g Fox BM, Xiao X, Antony S, Kohlhagen G, Pommier Y, Staker B, Stewart L, Cushman M. J. Med. Chem. 2003; 46:3275. 
[PubMed: 12852757] h Cho W-J, Park M-J, Imanishi T, Chung B-H. Chem. Pharm. Bull. 1999; 47:900. [PubMed: 10399841]

6. Black DA, Arndtsen BA. J. Org. Chem. 2005; 70:5133. [PubMed: 15960515]

7. For the preparation of 3a via hydrostannylation, see: Darwish A, Lang A, Kim T, Chong JM. Org. Lett. 2008; 10:861. [PubMed: 18237179]

8. Compare to our original method reported in reference $3 \mathrm{a}$.

9. Variations in the $\mathrm{CuCl}$ load and the excess of stannane $\mathbf{3 a}$ in reactions under the conditions described in Scheme 1 affected the yields of amide 4a: (i) $20 \mathrm{~mol} \% \mathrm{CuCl}, 2.0$ equiv 3a gave $4 \mathbf{a}$ in $80 \%$ yield; $20 \mathrm{~mol} \% \mathrm{CuCl}, 1.0$ equiv 3a gave $4 \mathbf{a}$ in $62 \%$ yield; (iii) $10 \mathrm{~mol} \% \mathrm{CuCl}, 1.5$ equiv 3a gave $4 \mathbf{a}$ in $67 \%$ yield.

10. Zeni G, Larock RC. Chem. Rev. 2000; 100:3009. [PubMed: 11749313] Brown D, Grigg R, Sridharan V, Tambyrajah V. Tetrahedron Lett. 1995:8137. For a review on the synthesis of heterocycles via transition metal catalysis, see: D'Souza DM, Müller TJ. J. Chem. Soc. Rev. 2007; 36:1095.

11. ${ }^{1} \mathrm{H}$ NMR analysis of the crude reaction mixtures indicated the presence of traces of a diastereomeric indenoisoquinoline. Isolation via chromatography followed by trituration from hexanes afforded a pure single diastereomer 5a. The relative stereochemistry was asssigned based on the comparison of the spectroscopic data with the spectroscopic data recorded for heterocycle $\mathbf{5 j}$, the structure of which was established by X-ray crystallography (vide infra).

12. a Jeffery T. Tetrahedron Lett. 1985; 26:2667.b Jeffery T. J. Chem. Soc. Chem. Commun. 1984:1287.

13. For the preparation of the stannanes, see: Darwish A, Chang JM. J. Org. Chem. 2007; 72:1507. [PubMed: 17253749]

14. The relative stereochemistry in heterocycle 50 was established via ${ }^{1} \mathrm{H}$ NMR NOE study and the structure of $\mathbf{5} \mathbf{~} \mathbf{m}$ was assigned accordingly. For details see the Supporting Information.

15. Black DA, Arndtsen BA. Org. Lett. 2004; 6:1107. [PubMed: 15040734]

16. Grigg R, Loganathan V, Sridharan V. Tetrahedron Lett. 1996; 37:3399.

17. Structures of all the remaining indenoisoquinolines were assigned accordingly. The structure assignment is also supported by $2 \mathrm{D}$ NMR and NOE ${ }^{1} \mathrm{H}$ NMR spectral studies performed on heterocycles $8 \mathbf{c}$ and $\mathbf{8 d}$ (see the Supporting Information).

Org Lett. Author manuscript; available in PMC 2013 December 23. 


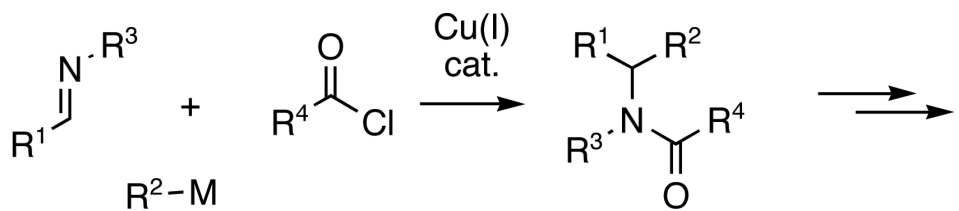

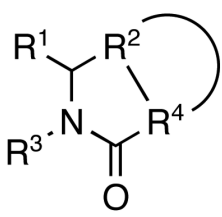

or

hexahydro- $1 H$-isoindolones (reference 3a)

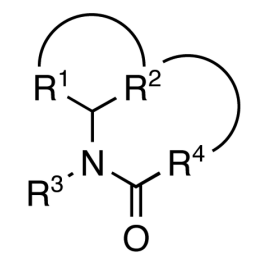

dihydroindeno[1,2c]isoquinolines (this work)

Figure 1.

The general strategy 


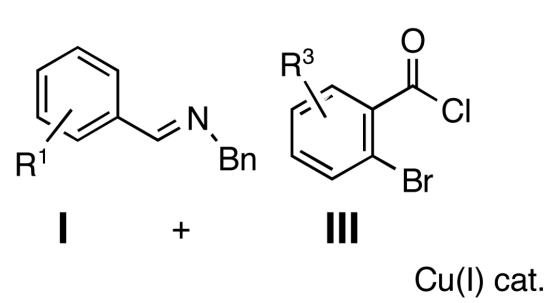<smiles>[R]C(=C)C(c1ccc([R])cc1)N(Cc1ccccc1)C(=O)c1ccccc1Br</smiles><smiles>[R][Ga]C#C[Hg]CC</smiles>

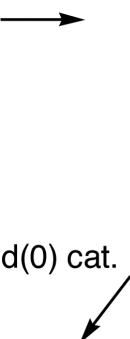<smiles>[R]C#CC(c1ccc([R])cc1)N(Cc1ccccc1)C(=O)c1ccpcc1Br</smiles>

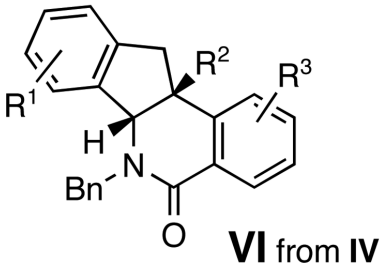<smiles>[R]c1c2ccc[Y7]([H])c2c2c1c1ccccc1c(=O)n2Cc1ccccc1</smiles>

Figure 2.

Strategy toward indenoisoquinolines 


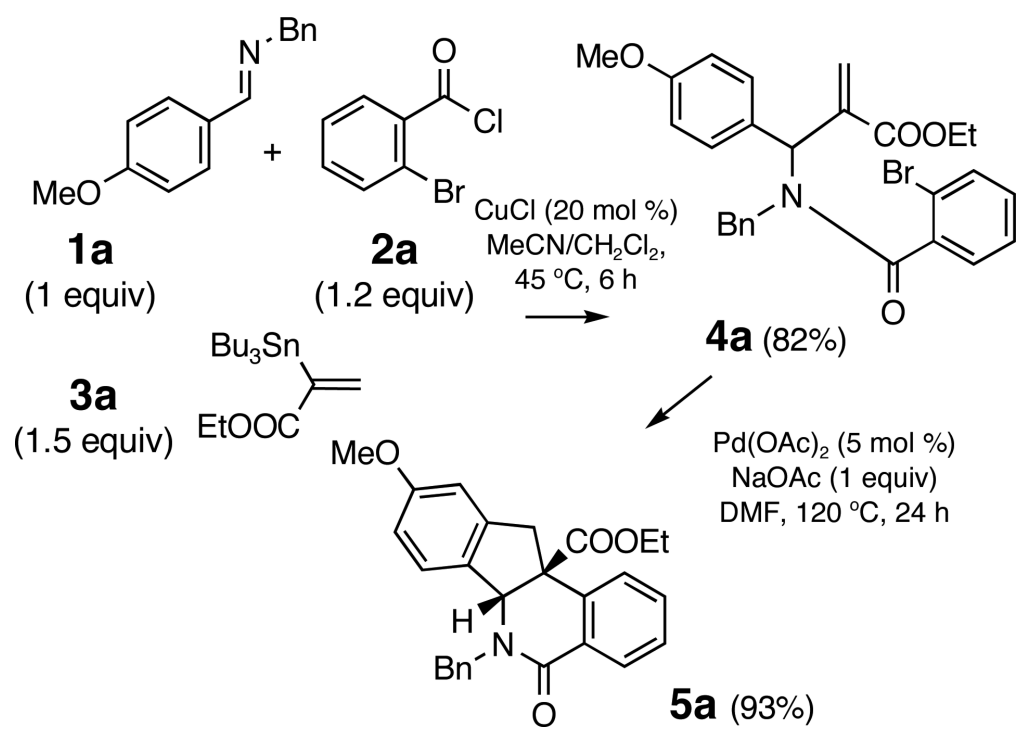

Scheme 1.

Protocol utilizing an isolated amide 
<smiles>COc1ccc(/C=N\c2ccccc2)cc1</smiles>

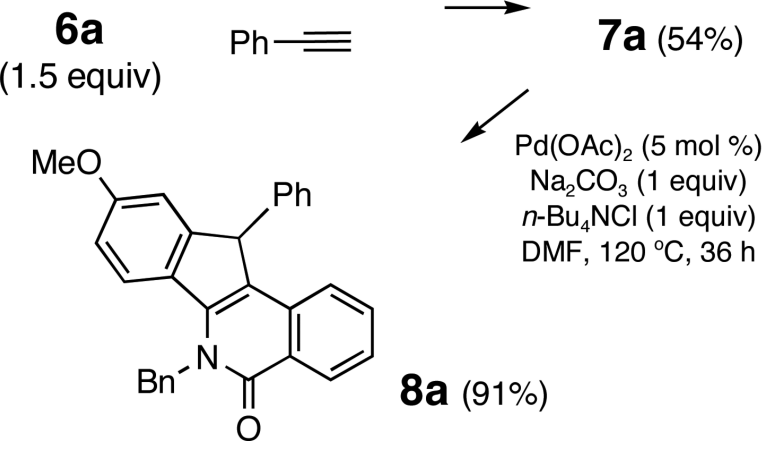

Scheme 2.

Protocol utilizing an isolated propargyl amide 


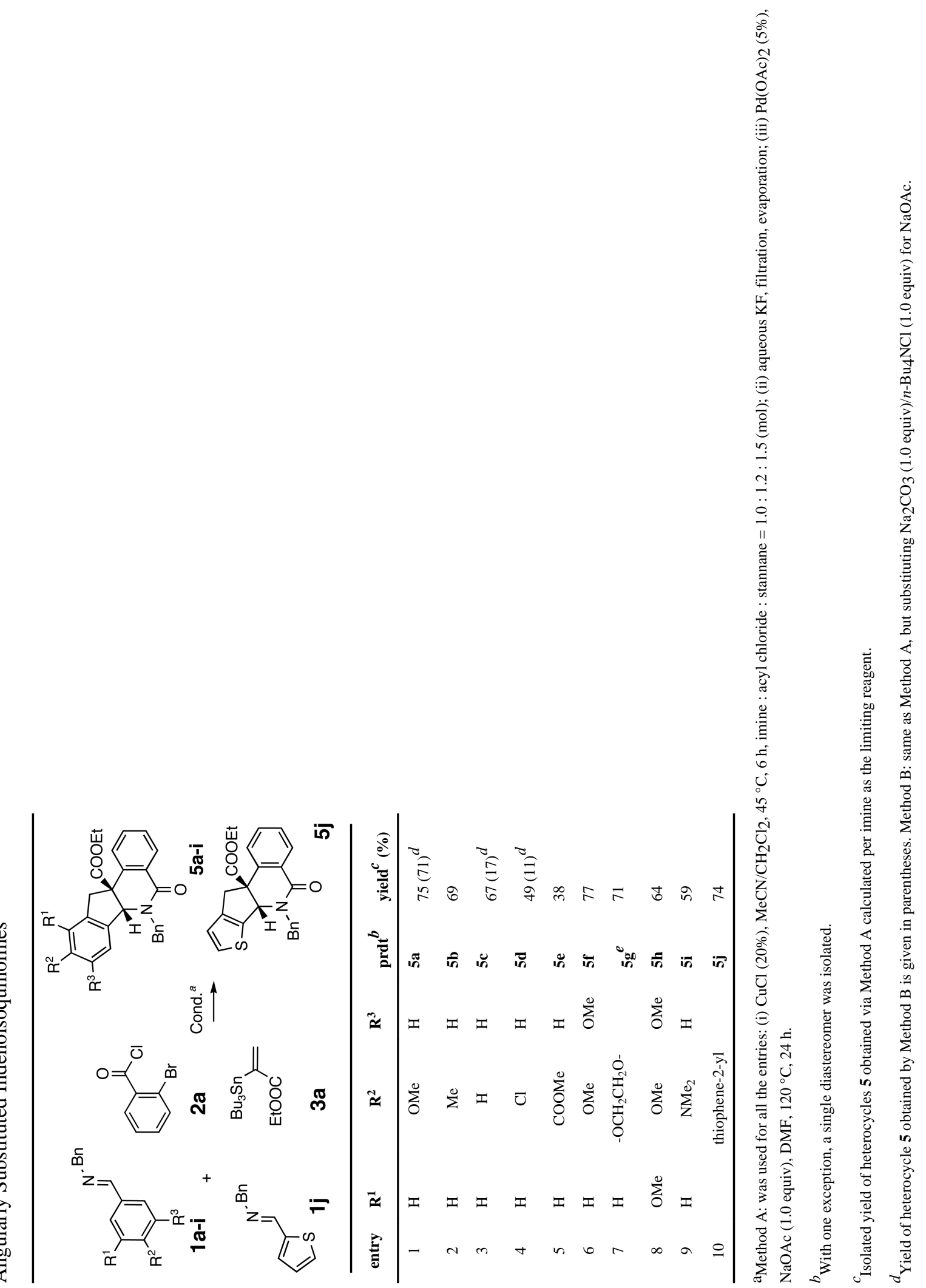




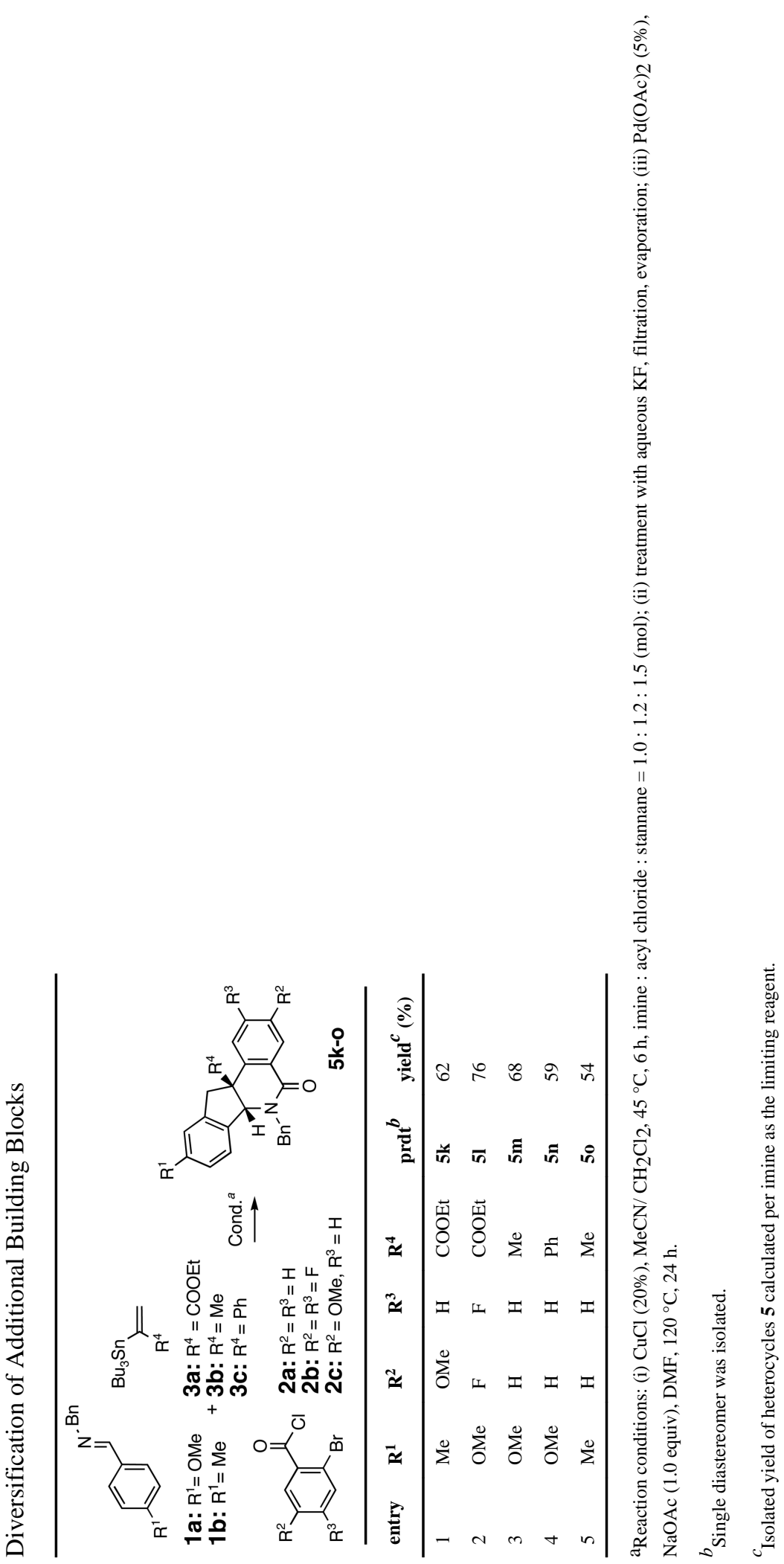

Org Lett. Author manuscript; available in PMC 2013 December 23. 
Table 3

Indenoisoquinolines with a benzylic substituent

$\mathbf{6 a}: \mathrm{R}^{2}=\mathrm{C}_{6} \mathrm{H}_{5}$
$\mathbf{6} \mathbf{C}: \mathrm{R}^{2}=$
$\mathrm{R}^{2}-\mathrm{MeC}_{6} \mathrm{H}_{4}$

aReaction conditions: (i) $\mathrm{CuCl}$ (20\%), $i$-PrEt $2 \mathrm{~N}$ (1.5 equiv) $\mathrm{MeCN}$, rt. $1 \mathrm{~h}$, imine : acyl chloride : alkyne = $1.0: 1.2: 1.5$ (mol); (ii) treatment with aqueous $\mathrm{KF}$, filtration, evaporation; (iii) $\mathrm{Pd}(\mathrm{OAc}) 2$ (5\%), $\mathrm{Na}_{2} \mathrm{CO}_{3}$ (1.0 equiv), $n$ - $\mathrm{Bu} 4 \mathrm{NCl}$ (1.0 equiv), DMF, $120^{\circ} \mathrm{C}, 36 \mathrm{~h}$.

${ }^{b}$ Single diastereomer was isolated.

${ }^{c}$ Isolated yield of heterocycles $\mathbf{8}$ calculated per imine as the limiting reagent. 